before CS was performed under regional anesthesia. By contrast, "in a confidential postal questionnaire among 297 French anesthesiologists, Benhamou ${ }^{3}$ found that only $23 \%$ of the respondents used prophylaxis before obstetric anesthesia.

Our study demonstrates that, in our institution, the incidence of spinal failure or excessive block necessitating GA/intubation was extremely low. Therefore, routine prophylaxis may not be necessary prior to spinal anesthesia. However, these results should be confirmed by a prospective, controlled studies. An antacid should be administered whenever GA is required.

Carin Hagberg MD

Tiberiu Ezri MD

Ezzat Abouleish MD

Houston, Texas, USA

References

1 Greenbalgh CA. Obstetric anesthesia. In: Greenhalgh CA, McLean JL. A Survey of Acid Aspiration in Academic Departments of United States and Canada: S.O.A.P Abstract Book, 1993: 6.

2 Plumer MH, Rothman R How anesthesiologists practice obstetric anesthesia: responses of practicing obstetric anesthesiologists at the 1993 meeting of the Society for Obstetric Anesthesia and Perinatology. Reg Anesth 1996; 21: 49-60.

3 Benhamou D. French obstetric anesthesia and acid aspiration prophylaxis. Eur J Anaesth 1993; 10: 27-32.

\section{Hypertensive response to warm "car- diac" irrigation in a patient with a total artificial heart}

Warm irrigation of the pericardial pouch causes tachycardic and hypertensive responses in patients undergoing cardiac surgery. ${ }^{1}$ Proposed but unverified mechanisms include reflex sympathetic stimulation mediated by mediastinal receptors and involving the heart. We report an unusual case that may help explain the mechanisms involved.

A 49-yr old woman required a CardioWest total artificial heart (CardioWest Inc., Tucson, Ariz.) as a bridge to transplant. ${ }^{2}$ Cardiac output of the mechanical heart is dependent on selected rate and on filling of the two independent ventricular cavities. Increasing atrial pressure increases stroke volume and, since rate is constant, cardiac output. On postoperative day three, the patient required evacuation of intrathoracic clots under general anesthesia. Heart rate was set at
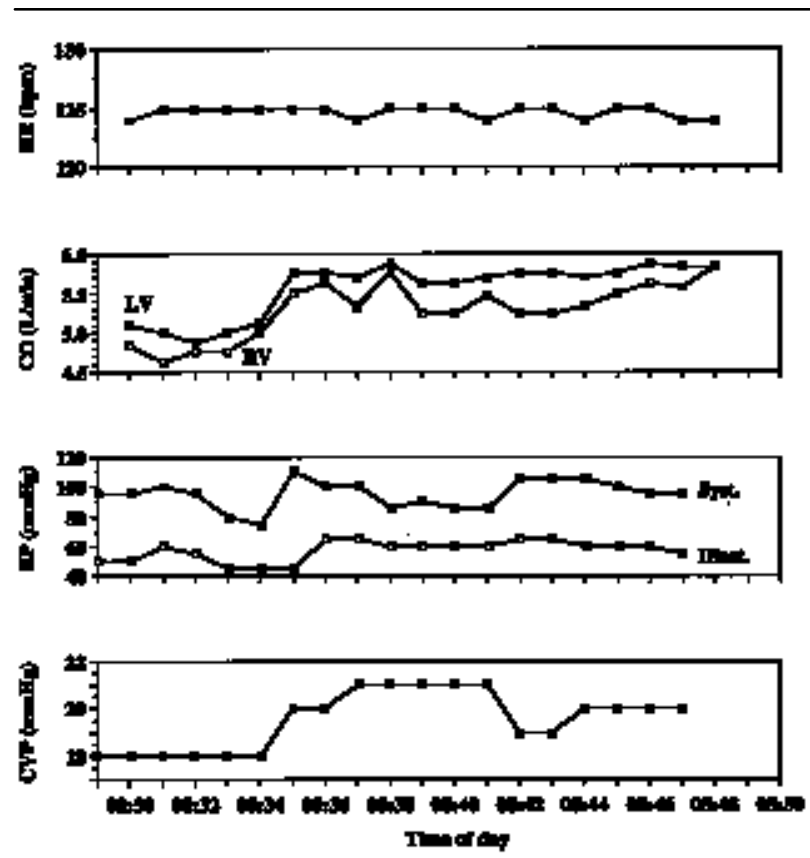

FIGURE

125 beats $\mathrm{min}^{-1}$ and at the end of an uneventful operation, the patient was hemodynamically stable and required no vasopressors. The surgeon then irrigated the thoracic cavity with approximately $600 \mathrm{~mL}$ of warm $\left(37^{\circ} \mathrm{C}\right)$ saline. Blood pressure increased abruptly (Figure) despite the absence of heart and originating great vessels. Data from the mechanical heart console showed that the filling volume and output of both ventricles had increased by approximately $10 \%$.

This case suggests that an increase in preload involving the caval veins in response to warm irrigation increased filling of the mechanical heart and augmented cardiac output, accounting for the increase in blood pressure. This rare event provides evidence (albeit anecdotal) that increased vascular tone may be an important mechanism responsible for the "hypertensive" response to warm irrigation in patients undergoing cardiac surgery.

Patrice Aubin MD

Jean-François Hardy MD

Michel Carrier MD

Montréal, Québec

References

1 Lingaraju N, Horrow JC, Colonna-Romano P, Strong $M D$. Haemodynamic consequences of warm cardiac 
irrigation during cardiac surgery. Can J Anaesth 1994;

41: 384-6.

2 Copeland JG, Pavie A, Duveau D, et al. Bridge to transplantation with the CardioWest total artificial heart: the international experience 1993 to 1995 . J

Heart Lung Transplant 1996; 15: 94-9.

\section{Erratum}

Acuda Listing

The Acuda listing which appeared in the October issue of the Canadian Journal of Anesthesia was unfortunately incorrect. We have therefore reprinted the corrected copy in this issue. 